Abstract

\title{
Serologic Analysis of Hepatitis E Virus Infection in Patients with Kidney-Related Illnesses ${ }^{\dagger}$
}

\author{
Martynas Simanavičius 1,*, Arūnẻ Verbickaitė 1, Paulius Lukas Tamošiūnas 1, \\ Ernesta Mačionienè ${ }^{2}$ and Indrè Kučinskaitè-Kodzè ${ }^{1}$ \\ 1 Life Sciences Center, Institute of Biotechnology, Vilnius University, 10257 Vilnius, Lithuania; \\ arune.verbickaite@gmc.vu.lt (A.V.); paulius.tamosiunas@bti.vu.lt (P.L.T.); indre.kodze@bti.vu.lt (I.K.-K.) \\ 2 Institute of Clinical Medicine, Faculty of Medicine, Vilnius University, 03101 Vilnius, Lithuania; \\ ernestabra@gmail.com \\ * Correspondence: martynas.simanavicius@bti.vu.lt \\ † Presented at Viruses 2020-Novel Concepts in Virology, Barcelona, Spain, 5-7 February 2020.
}

Published: 16 June 2020

\begin{abstract}
Hepatitis E is a globally distributed human disease caused by the hepatitis E virus (HEV). HEV is a positive-sense, single-stranded RNA virus that belongs to the family Hepeviridae. Within the genus Orthohepevirus, seven HEV genotypes infect various mammalian hosts. HEV genotypes HEV-1 to HEV-4 and HEV-7 can infect humans. HEV-3 is zoonotic with the domestic pig, wild boar, deer and other mammalian species as reservoirs. HEV-3 is an underestimated emerging threat which is spread across Europe. It is transmitted through undercooked pork meat or other products, and with blood components through transfusions. HEV-3 infection in immunocompetent patients is self-limiting and clinically asymptomatic. However, immunocompromised individuals are at a high risk of developing chronic hepatitis E. Chronic infection may lead to life-threatening liver cirrhosis. Patients with kidney transplants or kidney-related illnesses are in this risk group. In this study, a serologic analysis of blood samples obtained from kidney transplant recipients, patients with chronic kidney disease, patients under dialysis and healthy controls was performed. A prevalence of anti-HEV antibodies was assessed by commercial and in-house ELISAs.
\end{abstract}

Keywords: hepatitis E virus; serologic assay; kidney-related illnesses; humans

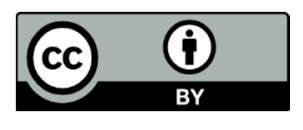

(C) 2020 by the authors. Licensee MDPI, Basel, Switzerland. This article is an open access article distributed under the terms and conditions of the Creative Commons Attribution (CC BY) license (http://creativecommons.org/licenses/by/4.0/). 